\title{
Personal and professional factors influencing career choice regret during the COVID-19 pandemic
}

\author{
Mary Kathryn Gaffney* \\ School of Nursing, University of South Carolina Aiken, United States
}

Received: February 9, 2021

Accepted: March 5, 2021

Online Published: March 16, 2021

DOI: $10.5430 /$ jha.v10n1p40

URL: https://doi.org/10.5430/jha.v10n1p40

\begin{abstract}
Objective: Many healthcare workers (HCWs) have been subjected to additional workplace and personal stressors during the COVID-19 pandemic. Some stressors may be more likely to contribute to career choice regret and the decision to leave the healthcare profession. Loss of critical numbers of personnel could leave healthcare systems without a ready, capable workforce. The purpose of this research was to determine which personal and professional characteristics increased frequency of career choice regret.

Methods: An international, cross-sectional survey was conducted to determine if specific personal and professional characteristics were associated with career choice regret and intent to leave. One short-answer item was included in the 20-item survey. The sample consisted of 874 English-speaking HCWs from 18 countries with representation of various practice settings, disciplines, ages, and years in healthcare.

Results: Significant correlations between pre- and intra-pandemic frequency of thoughts about leaving the healthcare profession were observed. Ordinal regression analyses were conducted, finding significant relationships between career regret thoughts and female gender, age, and death of a family member or friend. Death of a coworker was not associated with increased thoughts of leaving the healthcare profession. Themes from the short-answer item included fatigue, anger, doubt, fulfillment, and the pandemic as a journey.

Conclusions: Healthcare systems may be vulnerable to a loss of HCWs due to the effects of working during the COVID-19 pandemic. Hospital and health system executives need to understand the current threats to the stability of the workforce and develop strategies to prevent attrition of skilled, capable professionals.
\end{abstract}

Key Words: COVID-19, Healthcare workforce, Career choice regret, Healthcare systems, Staff turnover, Workforce stability

\section{INTRODUCTION}

The aftermath of the SARS-CoV-2 pandemic could be one in which many healthcare workers (HCWs) question their choice of career and ultimately opt to leave the healthcare workforce. Such an event could have a crippling effect on healthcare systems' ability to maintain a ready, capable staff. For example, during the early period of the SARS-CoV-2 outbreak in South Korea, a mere $8 \%$ of nurses considered quit- ting their job. ${ }^{[1]}$ By July 2020, individuals associated with COVID-19 units reported a markedly lower likelihood of remaining in their current jobs than peers not associated with COVID-19 units. ${ }^{[2]}$ Later in 2020, reports of career choice regret varied from nearly $16 \%{ }^{[3]}$ to a vast majority. ${ }^{[4]}$ Though many may be revisiting their career choice, the SARS-CoV-2 pandemic potentially could help some HCWs reaffirm their career choice and experience a greater sense of purpose and

*Correspondence: Mary Kathryn Gaffney; Email: maryg @ usca.edu; Address: School of Nursing, University of South Carolina Aiken, United States. 
professional identity. ${ }^{[5,6]}$

Several factors could contribute to a post-pandemic loss of $\mathrm{HCW}$ from the workforce. During the pandemic, HCWs have been confronted with repeated, sustained surges of high-acuity patients, limited resources, moral distress, and the demise and death of multiple patients. ${ }^{[7-9]}$ With the burden of additional stress, HCWs are at greater risk for shortand long-term effects on both mental and physical health, including physical and mental fatigue, depression, anxiety, insomnia, and avoidance. ${ }^{[10,11]}$ These manifestations, all of which may have been exacerbated by the pandemic, ${ }^{[12]}$ are commonly associated with burnout. ${ }^{[7,13]}$ For some HCWs, feelings of burnout may strengthen the urge to quit, both the job and the profession. ${ }^{[4,14]}$

Other factors may contribute to HCWs' career choice doubts, such as the fear and anxiety associated with caring for persons with an easily transmissible disease. ${ }^{[6]}$ Since the start of the pandemic, many HCWs have struggled with the fear of infecting and losing loved ones and coworkers to the coronavirus disease (COVID-19). ${ }^{[15-17]} \mathrm{HCW}$ are vulnerable to the disease too, though exposure is more likely to occur through community spread and when working outside of units designated for patients with COVID-19. ${ }^{[18]}$ In the event of a COVID-19-related illness or death of a family member, friend, or coworker, HCWs may experience post-traumatic stress syndrome, ${ }^{[19]}$ ongoing anxiety and depression, ${ }^{[20]}$ and signs of burnout, ${ }^{[21]}$ all of which are associated with greater risk of turnover or intent to leave the profession.

The purpose of this research was to determine if specific personal and professional characteristics are associated with increased frequency of career choice regret.

\section{MeTHODS}

\subsection{Participants}

This international cross-sectional study of healthcare professionals was assessed and approved by the university's institutional review board. To be eligible to participate, individuals had to be licensed or qualified healthcare professionals who provided face-to-face care for persons with known SARS-CoV-2 infections.

To recruit participants, the author joined social media groups for HCWs. Once admitted to the groups, the author posted a letter of invitation and link to the web-based survey site in the general discussion area. Participation was voluntary, anonymous, and not incentivized. Participants were encouraged to share the link with other HCWs to recruit persons who are not active on social media. The survey remained open for a period of two weeks.

Published by Sciedu Press

\subsection{Instrument}

The survey consisted of 20 items, 11 of which were demographic in nature and required categorical responses. Demographic items included response options necessary for later identification of those who were not licensed or qualified professionals, those who had not cared for patients with COVID-19, and those who were students. For the twelfth item, respondents were asked to provide one or two words to describe their feelings about working during the pandemic. The remaining eight items will undergo analysis at a later date.

\subsection{Data analysis}

Statistical analyses were conducted using SPSS v. 26 software. Pre- and intra-pandemic frequency of thoughts of leaving the healthcare profession were evaluated for strength of association as signified by Kendall's tau-b coefficient. To assess associations between personal and professional characteristics and frequency of thoughts of leaving the healthcare profession, ordinal logistic regressions were conducted. The level of statistical significance was $p<.05$.

\section{RESUlts}

A total of 1,249 responses were received. Respondents who were not licensed or qualified, those who indicated they had not provided care for persons with COVID-19, and/or those who identified as students were removed, leaving a final sample of 874 . Because the survey required a response for each item, no data were missing.

Respondents represented 18 nations, with the greatest number from North America (89.8\%), followed by Europe (4.9\%), Australia and New Zealand (3.4\%), and Asia and Africa (1.8\%). The age ranges of respondents were evenly distributed. Most respondents were female (85.3\%), which was expected considering that nursing, the largest responding group (78.8\%), is predominantly a female profession. Other professions included prehospital HCWs such as paramedics and emergency medical technicians $(11.1 \%)$, physicians (6.52\%), and providers of rehabilitation services (3.55\%). Years in the healthcare profession and primary areas of practice characteristics were more evenly distributed (see Table 1). Respondents also identified if they had experienced COVID19-related death of a family or friend $(12.8 \%)$, a coworker $(18.3 \%)$, or both $(5.5 \%)$.

\subsection{Inferential statistics}

Pre- and intra-pandemic frequency of doubt about choosing a healthcare profession were evaluated using Kendall's tau to establish the strength of the relationship between the two (see Table 2). In addition, ordinal logistic analysis was conducted 
to evaluate the effect of personal and professional characteristics on the frequency of career choice regrets. Concerning pre-pandemic career choice regret, no significant relationships were observed between participant age, geographic area of residence, profession, and primary clinical setting, although associations were observed with gender and years as a HCW (see Table 3). A second analysis was conducted to evaluate the relationships between sample characteristics and intra-pandemic career choice regret. This analysis also assessed the effect of COVID-19-related deaths of coworkers and of family and friends on career choice regrets (see Table 4).

Table 1. HCWs' experience in healthcare

\begin{tabular}{lcc}
\hline Primary Area & $\mathbf{n}$ & $\mathbf{\%}$ \\
\hline Acute Care & 345 & 39.47 \\
Critical Care & 371 & 42.45 \\
Outpatient & 109 & 12.47 \\
Long-term Care* & 49 & 5.61 \\
\hline Years as HCW & $\mathbf{n}$ & $\mathbf{\%}$ \\
\hline <2 years & 65 & 7.44 \\
2-5 years & 151 & 17.28 \\
6-10 years & 185 & 21.17 \\
11-20 years & 247 & 28.26 \\
21-30 years & 138 & 15.79 \\
$>$ 30 years & 88 & 10.07
\end{tabular}

Note. Long-term care ${ }^{*}=$ personal care home, nursing home, or other residential care site

\subsection{Qualitative analysis}

Responses from the short-answer item underwent independent thematic analysis by two doctorate-prepared individuals.
Several discrete themes emerged, illustrating predominant emotions and experiences. Many HCWs' responses revealed more than one theme and, in so doing, conveyed the dynamic nature of the situation.

Table 2. Frequency of healthcare profession regret

\begin{tabular}{lll}
\hline & Pre-pandemic & Intra-pandemic \\
\hline Never & $306(35.01 \%)$ & $190(21.74 \%)$ \\
Rarely & $344(39.36 \%)$ & $203(23.23 \%)$ \\
Sometimes & $191(21.85 \%)$ & $296(33.87 \%)$ \\
Often & $33(3.78 \%)$ & $185(21.17 \%)$ \\
\hline
\end{tabular}

Note. Kendall's tau coefficient .496, $p<.001$

\subsubsection{Fatigue}

Comments conveyed the depth of both physical and emotional fatigue experienced by healthcare professionals. Many attributed physical fatigue to PPE, describing themselves as "air hungry with masks", "dyspneic" and "overheated". One HCW described the experience as "spiritually, emotionally, and physically exhausting", while another defined the experience as "soul sucking". Respondents reported sadness, difficulty sleeping, being ethically challenged, feeling isolated, and being "burned out".

\subsubsection{Fear and vulnerability}

Many respondents described their experience of caring for patients with COVID-19 with terms suggesting fear for personal safety as well as that of loved ones at home. Although no respondents directly mentioned fear of dying from the disease, some used descriptors such as "terrifying", "dangerous", and "unsafe" to describe the experience. Repeatedly, respondents reported feeling unprotected and ill-equipped in an "unrelenting" and "dark" environment, one in which they expressed a sense of powerlessness to reduce perceived risks.

Table 3. Pre-pandemic predictors of healthcare profession regret

\begin{tabular}{|c|c|c|c|c|c|c|c|}
\hline \multirow{2}{*}{ Predictor/Effect } & & \multirow{2}{*}{$\boldsymbol{B}$} & \multirow{2}{*}{$S E$} & \multirow{2}{*}{ Wald } & \multirow{2}{*}{ Sig. } & \multicolumn{2}{|c|}{$95 \% \mathrm{CI}$} \\
\hline & & & & & & Lower & Upper \\
\hline \multirow[t]{3}{*}{ Gender } & Male & -.524 & .184 & 8.141 & .004 & -.884 & -.164 \\
\hline & $<2$ years & -1.010 & .314 & 10.377 & .001 & -1.625 & -.396 \\
\hline & $2-5$ years & -.281 & .248 & 1.287 & .257 & -.767 & .205 \\
\hline \multirow[t]{3}{*}{ Years as HCW } & $6-10$ years & -.285 & .240 & 1.410 & .235 & -.755 & .185 \\
\hline & $11-20$ years & .123 & .229 & .288 & .591 & -.325 & .570 \\
\hline & $21-30$ years & .218 & .251 & .755 & .385 & -.274 & .711 \\
\hline
\end{tabular}

Note. $B=$ estimate; $S E=$ standard error; degrees of freedom = 1. Outpatient includes home health, community health, and clinic settings 
Table 4. Intra-pandemic predictors of healthcare profession regret

\begin{tabular}{|c|c|c|c|c|c|c|c|}
\hline \multirow{2}{*}{ Predictor/Effect } & & \multirow{2}{*}{ B } & \multirow{2}{*}{$S E$} & \multirow{2}{*}{ Wald } & \multirow{2}{*}{ Sig. } & \multicolumn{2}{|c|}{$95 \% \mathrm{CI}$} \\
\hline & & & & & & Upper & Lower \\
\hline \multirow[t]{3}{*}{ Gender } & Male & -.735 & .178 & 17.014 & .000 & -1.084 & -.386 \\
\hline & $<2$ years & .144 & .298 & .231 & .630 & -.441 & .729 \\
\hline & $2-5$ years & .224 & .244 & .842 & .359 & -.254 & .702 \\
\hline \multirow[t]{3}{*}{ Years as HCW } & $6-10$ years & .459 & .235 & 3.808 & .051 & -.002 & .919 \\
\hline & $11-20$ years & .632 & .226 & 7.820 & .005 & .189 & 1.075 \\
\hline & 21-30 years & .415 & .247 & 2.819 & .093 & -.070 & .900 \\
\hline Family member or friend COVID death & Yes & .377 & .191 & 3.894 & .048 & .003 & .751 \\
\hline
\end{tabular}

Note. $B=$ estimate; $S E=$ standard error; degrees of freedom $=1$

\subsubsection{Anger}

HCWs expressed anger that appeared directed toward hospital or healthcare system administrators. They reported feeling pressured to work. Several revealed "I do not enjoy my job any more." Other thematic descriptors included "infuriated", "misled", "abandoned", "abused" and "betrayed". HCWs did not directly or indirectly describe anger toward coworkers or peers, although a few comments referred to PPE deficits. Many HCWs voiced how they felt expendable, using phrases such as "sacrificial lambs" and "sheep left for slaughter".

\subsubsection{Doubters}

Despite caring for persons infected by the virus, not all HCWs were in agreement about the pandemic and its effect. A few respondents mirrored the doubt sewn by some political and non-healthcare groups. These individuals used terms such "blown out of proportion", "PLANdemic", "overblown panic", "big hoax" and "it's our job, no bigger than Ebola, flu" to describe their experience.

\subsubsection{Fulfillment}

A comparatively small number of respondents conveyed positive feelings about providing patient care during the pandemic. For some, this was a "life-changing" experience that left them feeling gratified and proud. Others described the experience as one in which they were "privileged" to participate, feeling "humbled" and "honored". A few respondents suggested that providing care during the pandemic was a "duty" or "mission", part of a greater calling. Some suggested that the experience increased appreciation of HCWs, offering opportunity for greater respect and empowerment. Several respondents thrived on the challenges by drawing on their adaptability and determination as they responded to this

Published by Sciedu Press "bat shit crazy but awesome" experience.

\subsubsection{The pandemic as a journey}

HCWs' comments revealed how the pandemic affected them on multiple levels simultaneously, both emotionally and professionally. Responses included "exhilarating/terrifying", "exhausting, fulfilling", "overwhelmed, honored", "proud, worried", "scary, fascinating", and "exhausting, rewarding". The weight of the "subtle panic" and "toxic challenge" of the pandemic continuously shaped HCWs as the experience unfolded.

\section{Discussion}

The experience of caring for patients with COVID-19 is complex and complicated, making interpretation of the data equally challenging. The considerable increase in the frequency of career choice regret is clear, suggesting that a number of HCWs may leave the healthcare profession because of their experiences during the pandemic. This is consistent with findings from a previous study and demonstrates how these thoughts tend to multiply as the duration of the pandemic extends. ${ }^{[1-3]}$

Frequently, narrative comments exposed an undercurrent of fear and vulnerability, which alone could have been responsible for increased thoughts about career choice regret. Comments characterized key aspects of distress, including difficulty sleeping, persistent anxiety, and physical and emotional fatigue, demonstrating the current threats to $\mathrm{HCWs}$ ' general well-being. ${ }^{[5,6]}$ In revealing this information, respondents also outlined critical manifestations of burnout as a potential threat to the integrity of the healthcare workforce. ${ }^{[4,7,9,13,14]}$

Comments acknowledged the inherent risk to self and oth- 
ers from the virus, including family, friends, and coworkers. ${ }^{[8,15,17]}$ These feelings may have intensified for the nearly $13 \%$ of respondents who experienced the death of a family member or friend due to COVID-19 and for the $18 \%$ who lost a coworker. Many signs of grief are consistent with those described by the vast majority of the sample as the physical and mental manifestations of stress from providing care to persons with COVID-19. Caught unprepared, both professionally and personally, for the volume of death and suffering, ${ }^{[10]}$ the pandemic took a toll on HCWs and left them reeling from the experience. ${ }^{[11,12,16]}$ Distinguishing between grief and burnout, post-traumatic stress syndrome, and other psychological phenomena may be impossible without a more direct line of inquiry; regardless, the outcome has the potential to be the same: leaving the profession. ${ }^{[19-21]}$

Though some looked upon this event as a catalyst to leaving the healthcare profession, others found the experience galvanized their commitment. ${ }^{[5]}$ Many seized the opportunities presented by the pandemic and, as a result, experienced growth, creativity, empowerment, and respect. The pandemic expanded their horizons ${ }^{[5]}$ and, for some, possibly reversed previous thoughts of career regret.

That many HCWs described their experience in two seemingly contradictory ways illustrates the complexity of working in healthcare during a pandemic. Dichotomous comments paint a picture of the fluidity of the situation as patient surges, short staffing, multiple patient death experiences, and limited PPE availability changed over time. These responses offer a level of honesty not found in those with only one sentiment and provide insight into the day-to-day reality of the experience.

One theme from the narrative responses bears deeper exploration than is possible in this study: anger. Comments conveyed mistrust of leadership at multiple levels, including hospital, community, and national. Rebuilding the trust of HCWs in the wake of inadequate PPE and other discomfort- ing patient care conditions will be necessary to maintain a capable healthcare workforce. This trust will need to be restored at interpersonal levels, too, because of outliers within the healthcare profession who doubted the large-scale effects of the pandemic on populations, $\mathrm{HCW}$, and healthcare systems.

\section{Limitations}

This study had several limitations. Because no pre-pandemic assessment of participants' career choice regrets was possible, recollection of frequency of these thoughts is subject to bias. The sample predominantly included respondents working in North America, so results may be more applicable to this population. Respondents were not asked to disclose if they had been "up-skilled" to care for patients in a higher acuity setting when critical care units needed assistance. In addition, respondents were not asked if they worked in known hotspots such as New York City. Without additional information, environmental or situational influence on career choice regret cannot be assessed. Lastly, because of the anonymous nature of the survey, the same group of persons cannot be re-evaluated to determine if career choice regrets return to baseline levels after the pandemic ends.

\section{Conclusions}

The SARS-CoV-2 pandemic has challenged healthcare professionals and systems alike. During pre-pandemic times, thoughts of career choice regret were less common, but as the pandemic continued, these thoughts became more frequent. Factors such as female gender, years as a healthcare professional, fear, anger, fatigue, and COVID-19-related deaths of family and friends are associated with increased frequency of these thoughts. Hospital and health system executives need to understand the current threats to the stability of the professional workforce and take action to prevent attrition.

\section{CONFLICTS OF INTEREST DisClOSURE}

The authors declare they have no conflicts of interest.

\section{REFERENCES}

[1] Jang Y, You M, Lee SY, et al. Factors associated with hospital workers' intention to work in South Korea during the early stages of the COVID-19 outbreak. Disaster Med Public Health Prep. 2020, June 25. https://doi.org/10.1017/dmp. 2020.221

[2] Kim YJ, Lee SY, Cho JH. A study on the job retention intention of nurses based on social support in COVID-19 situation. Sustainability. 2020; 12: 7276. https://doi.org/10.3390/su12187276

[3] Chalal C, Govil N, Gupta N, et al. Stress, coping and attitudinal change towards medical profession during COVID-19 pandemic among health care professionals in India: A cross sectional study.
Indian J Mental Health. 2020; 7(3): 255-262. https ://doi .org/ 10.30877/I JMH. 7.3.2020.255-262

[4] Said RM, El-Shafei DA. Occupational stress, job satisfaction, and intent to leave: Nurses working on front lines during COVID-19 pandemic in Zagazig City, Egypt. Environ Sci Pollut Res. 2021; 28: 8791-8801. https://doi.org/10.1007/s11356-020-112 35-8 PMid:33067794 PMCid:PMC7567651

[5] Liu YE, Zhai ZC, Han YH, et al. Experiences of front-line nurses combating coronavirus disease-2019 in China: A qualitative analysis. Public Health Nurs. 2020; 37: 757-763. PMid: 32677072. https://doi.org/10.1111/phn.12768 
[6] Sperling D. Ethical dilemas, perceived risk, and motivation among nurses during the COVID-19 pandemic. Nurs Ethics. 2021; 28(1): 9-22. PMid: 33000673. https ://doi.org/10.1177/09697330 20956376

[7] Martinez-Lopez JA, Lazaro-Perez C, Gomez-Galan J, et al. Psychological impact of COVID-19 emergency on health professionals: Burnout incidence at the most critical period in Spain. J Clin Med. 2020 Sep 20; 9(9): 3029. PMid: 32962258. https: //doi.org/10.3390/jcm9093029

[8] Moradi Y, Baghaei R, Hosseingholipour K, et al. Challenges experience by ICU nurses throughout the provision of care for COVID-19 patients: A qualitative study. J Nurs Manag. 2021; 00: 1-10. PMid: 33480145. https://doi.org/10.1111/jonm. 13254

[9] Rangachari P, Woods JL. Preserving organizational resilience, patient safety, and staff retention during COVID-19 requires a holistic consideration of the psychological safety of healthcare workers. Int J Environ Res Public Health. 2020; 17: 4267. PMid: 32549273. https://doi.org/10.3390/ijerph17124267

[10] Galvin J, Richards G, Smith AP. A longitudinal cohort study investigating inadequate preparation and death and dying in nursing students: Implications for the aftermath of the COVID-19 pandemic. Front Psychol. 2020, Aug 25. https://doi .org/10.31234/osf . io/6pq38

[11] Sun N, Wei L, Shi S, et al. A qualitative study on the psychological experience of caregivers of COVID-19 patients. Am J Infect Control. 2020; 48(6): 592-598. PMid: 32334904. https: //doi.org/10.1016/j.ajic.2020.03.018

[12] Pearman A, Hughes ML, Smith EL, et al. Mental health challenges of United States healthcare professionals during COVID-19. Front Psychol. 2020; 11: 2065. PMid: 32903586. https://doi.org/10 .3389/fpsyg. 2020.02065

[13] Jung H, Jung SY, Lee MH. Assessing the presence of post-traumatic stress and turnover intention among nurses post-Middle East Respiratory Syndrome outbreak: The importance of supervisor support. 2020; 68(7): 337-345. PMid: 32146875. https ://doi .org/10.1 $177 / 2165079919897693$
[14] Jyothindran R, d'Etienne JP, Marcum K, et al. Fulfillment, burnout and resilience in emergency medicine - Correlations and effects on patient and provider outcomes. PLoS ONE. 2020; 15(10): e0240934. PMid: 33075090. https://doi.org/10.1371/journal.pone .0240934

[15] Adams JG, Walls RM. Supporting the health care workforce during the COVID-19 global pandemic. JAMA. 2020; 323(15): 14391440. PMid: 32163102. https://doi.org/10.1001/jama. 202 0.3972

[16] Arnetz JE, Goetz CM, Arnetz BB, et al. Nurse reports of stressful situations during the COVID-19 pandemic: Qualitative analysis of survey responses. Int J Environ Res Public Health. 2020; 17: 8126. PMid: 33153198. https://doi.org/10.3390/ijerph17218126

[17] Cox CL. 'Healthcare heroes': Problems with media focus on heroism from healthcare workers during the COVID-19 pandemic. J Med Ethics. 2020; 46: 510-513. PMid: 32546658. https://doi.org/ $10.1136 /$ medethics-2020-106398

[18] Lentz RJ, Colt H, Chen H, et al. Assessing coronavirus disease 2019 (COVID-19) transmission to healthcare personnel: The global ACTHCP case-control study. Infect Control Hosp Epidemiol. 2020; 1-7. PMid: 32900402. https://doi.org/10.1017/ice.2020.455

[19] Rossi R, Socci V, Pacitti F, et al. Mental health outcomes among frontline and second-line health care workers during the coronavirus disease 2019 (COVID-19) pandemic in Italy. JAMA Network Open. 2020; 3(5): e2010185. PMid: 32463467. https ://doi.org/10.1 001/jamanetworkopen. 2020.10185

[20] Luceno-Moreno L, Talavera B, Garcia-Albuerne Y. Symptoms of posttraumatic stress, anxiety, depression, levels of resilience and burnout in Spanish health personnel during the COVID-19 pandemic. Int J Environ Res Public Health. 2020; 17(15): 5514. PMid: 32751624. https://doi .org/10.3390/ijerph17155514

[21] Abdelhafiz AS, Ali A, Ziady $\mathrm{HH}$, et al. Prevalence, associated factors, and consequences of burnout among Egyptian physicians during COVID-19 pandemic. Front. Public Health. 2020 Dec 3. PMid: 33344401. https://doi.org/10.3389/fpubh.2020.590190 